УДК 347.772:347.42(470+510)-047.34

https://doi.org/10.24866/1813-3274/2021-2/98-103

А. П. Рабец ${ }^{1}$, Дальневосточный федеральный университет,

г. Владивосток, Россия

E- mail: anita_trof@mail.ru

\title{
КОМПЕНСАЦИЯ ЗА НАРУШЕНИЕ ИСКЛЮЧИТЕЛЬНОГО ПРАВА НА ТОВАРНЫЙ ЗНАК: СРАВНИТЕЛЬНЫЙ АНАЛИЗ ЗАКОНОДАТЕЛЬСТВА РОССИИ И КНР
}

Аннотащия. В статье рассматриваются вопросы, касающиеся особенностей применения выплаты компенсации за нарушение исключительного права на товарный знак по законодательству России и КНР*. Отмечено, что выплата компенсации за нарушение исключительного права является самостоятельным способом защиты гражданских прав и относится к мерам гражданско-правовой ответственности наряду с возмещением убытков и взысканием неустойки. В исследовании проведён сравнительный анализ положений ГК РФ и Закона КНР «О товарных знаках» по вопросам, касающимся правовой природы указанного способы защиты, порядка выплаты компенсации и условий гражданско-правовой ответственности за нарушение исключительного права на товарный знак. Сделан вывод о том, что правовое регулирование в сфере взыскания компенсации за нарушение исключительного права на товарный знак в России и в КНР обладает рядом схожих характеристик. Выплата компенсации по законодательству обеих стран является способом защиты только исключительного права, а не иных интеллектуальных прав. В целом совпадают критерии определения размера компенсации, а также некоторые варианты её расчёта. В то же время имеются и определённые различия в правовом регулировании порядка выплаты компенсации, а также в особенностях применения данного способа защиты гражданских прав в судебной практике. К примеру, в российской правоприменительной практике существует определённый баланс между восстановительной и штрафной функцией рассматриваемой санкции, тогда как в КНР штрафная природа компенсации в ряде случаев выходит на первый план. Анализ

\footnotetext{
${ }^{1}$ Анна Петровна Рабец, кандидат юридических наук, доцент, доцент кафедры гражданского права и процесса Юридической школы, Дальневосточный федеральный университет, г. Владивосток, Россия.

Для циитирования: Рабец А. П. Компенсация за нарушение исключительного права на товарный знак: сравнительный анализ законодательства России и КНР // Азиатско-Тихоокеанский регион: экономика, политика, право. 2021. №. 2. C. 97-107. DOI https://doi.org/10.24866/1813-3274/2021-2/98-103.

* Перевод судебной практики КНР и доктринальных источников Китая на русский язык осуществил магистрант ЮШ ДВФУ Ван Чунь (Е- mail: van.chu@students.dvfu.ru).
}

(C) Рабец А. П., 2021 
особенностей выплаты компенсации с учётом специфики законодательства России и Китая позволяет взглянуть на рассматриваемый способ защиты исключительного права под другим углом и учесть положительный опыт обеих стран при совершенствовании законодательства в данной области.

Ключевые слова: интеллектуальная собственность, компенсация за нарушение исключительного права, товарный знак, интеллектуальные права, способы защиты гражданских прав, законодательство России, законодательство КНР, убытки, гражданско-правовая ответственность, правонарушение, вина.

Anna P. Rabets ${ }^{1}$, Far Eastern Federal University, Vladivostok, Russia

E- mail: anita_trof@mail.ru

\section{COMPENSATION FOR VIOLATION OF THE EXCLUSIVE RIGHT TO A TRADEMARK: A COMPARATIVE ANALYSIS OF THE LEGISLATION OF RUSSIA AND THE PRC}

Abstract. The article deals with the peculiarities of the application of compensation for violation of the exclusive right to a trademark under the laws of Russia and China*. It is noted that the payment of compensation for violation of an exclusive right is an independent method of protecting civil rights and refers to the measures of civil liability, along with compensation for losses and the recovery of penalties. The study conducted a comparative analysis of the provisions of the Civil Code of the Russian Federation and the Law of the China "On Trademarks" on issues related to the legal nature of these methods of protection, the procedure for paying compensation and the conditions of civil and legal liability for violation of the exclusive right to the trademark. It was concluded that the legal regulation in the field of recovery of compensation for violation of the exclusive right to a trademark in Russia and China has a number of similar characteristics. Thus, the payment of compensation under the laws of both countries is a way of protecting only the exclusive right, but not other intellectual rights. In general, the criteria for determining the amount of compensation, as well as some options for calculating it, coincide. At the same time, there are certain differences in the legal regulation of the procedure for paying compensation, as well as in the peculiarities of the use of this method of protecting civil

\footnotetext{
${ }^{1}$ Anna Petrovna Rabets, Candidate of Law Sciences, associate professor, associate professor of civil law and process of Law school, Far Eastern Federal University, Vladivostok, Russia.

Для цитирования: Rabets A. P. Compensation for violation of the exclusive right to a trademark: a comparative analysis of the legislation of Russia and the PRC // PACIFIC RIM: Economics, Politics, Law. 2021. No 2. P. 98-103. DOI https://doi.org/10.24866/1813-3274/2021-2/98-103.

* The translation of the judicial practice of the PRC and the doctrinal sources of China into Russian was carried out by Wang Chun, a master student of the FEFU YSH FEFU (E-mail: van.chu@students.dvfu.ru).
} 
rights in judicial practice. For example, in the Russian law enforcement practice there is a certain balance between the restorative and punitive functions of the sanction under consideration, while in China the punitive nature of compensation in some cases comes to the fore. Analysis of the peculiarities of compensation payments taking into account the specifics of the legislation of Russia and China allows us to look at the considered method of protecting exclusive law from a different angle and take into account the positive experience of both countries in improving legislation in this area.

Keywords: intellectual property, compensation for violation of an exclusive right, trademark, Intellectual rights, ways to protect civil rights, Russia legislation, PRC legislation, losses, civil liability, offence, guilt.

При нарушении исключительного права на товарный знак наиболее востребованным у отечественных правообладателей способом защиты является взыскание компенсации вместо возмещения убытков (п. 3 статьи 1252 ГК РФ; п. 4 статьи 1515 ГК РФ). Согласно п. 3 статьи 1252 ГК РФ одновременное взыскание компенсации и убытков за нарушение исключительного права не допускается. При этом не запрещено применение указанной санкции за правонарушение наряду с другими способами защиты гражданских прав (требованиями о пресечении действий, нарушающих право, о публикации решения суда о допущенном правонарушении и др.). При этом компенсация подлежит взысканию при доказанности факта правонарушения независимо от наличия убытков.

Специфике компенсации как способу защиты нарушенных прав посвящено достаточно много исследований [1, с. 48-55]. Однако до сих пор в доктрине и судебной практике остаются нерешёнными вопросы, касающиеся правовой природы и порядка определения размера компенсации. Принятие Конституционным Судом РФ постановлений, в которых оцениваются положения ГК РФ о компенсации на соответствие Конституции РФ, дало очередной импульс к обсуждению особенностей данной санкции [2; 3].

Так, некоторые учёные придерживаются «восстановительного» подхода к природе компенсации [4, с. 246]. Например, по мнению А. П. Сергеева, компенсация «по своей юридической природе представляет собой не какую-то особую меру гражданско-правовой ответственности, а является особым способом возмещения убытков, причинённых правообладателю нарушением его исключительного права. Её «особость» заключается в том, что потерпевший освобождается от обязанности доказывать размер убытков» [5, с. 68-79].

Другие авторы являются сторонниками «штрафной» природы рассматриваемой санкции, не отрицая при этом за ней и цели восстановления имущественного положения правообладателя. Например, В. О. Калятин считает, что «компенса- 
ция, предусмотренная частью четвёртой ГК РФ, носит явно штрафной характер», отмечая при этом эффективность механизма компенсации в плане предотвращения правонарушений [6, с. 18].

Полагаем, что выплата компенсации, в том числе и за нарушение исключительного права на товарный знак, является самостоятельным способом защиты гражданских прав и относится к мерам гражданско-правовой ответственности наряду с возмещением убытков и взысканием неустойки. При этом, являясь санкцией за бездоговорное гражданское правонарушение, компенсация выражается в обременениях в виде возложения на нарушителя дополнительных обязанностей. Указанный подход к правовой природе компенсации согласуется с позицией Конституционного Суда РФ, поддерживается в доктрине [7, с. 235] и отечественной судебной практике. Так, Л. А. Новосёлова отмечает, что «компенсация является мерой гражданско-правовой ответственности, поскольку применяется (1) между юридически равными субъектами, (2) по требованию и в пользу потерпевшей стороны, (3) для защиты частного имущественного права потерпевшего, (4) имеет преимущественной целью возмещение имущественных потерь правообладателя (компенсаторная, восстановительная функция)» [1, с. 48-55]. В свою очередь, Конституционный Суд РФ признал компенсацию в качестве «специального способа защиты исключительных прав на объекты интеллектуальной собственности», носящего штрафной характер и преследующего, в том числе, публичные цели пресечения нарушений в сфере интеллектуальной собственности (п. 3. 3, п. 4.2 Постановления Конституционного Суда РФ от 13 декабря 2016 г. № 28-П) [2].

Таким образом, компенсация за нарушение исключительного права на товарный знак как мера гражданско-правовой ответственности в соответствии с российским законодательством обладает двойственной природой. С одной стороны, указанная санкция имеет восстановительную (компенсаторную) функцию, ибо направлена на восстановление имущественной сферы правообладателя. Вместе с тем, как всякая юридическая ответственность компенсация осуществляет штрафную функцию в отношении правонарушителя.

В КНР, как и в России, выплата компенсации является одним из самых распространённых способов защиты права на товарный знак, позволяющим эффективно защищать интересы правообладателей. Порядок применения данной санкции регулируется Законом КНР «О товарных знаках», принятом на 24 заседании Постоянного комитета Всекитайского собрания народных представителей пятого созыва 23 августа 1982 г. В настоящее время указанный закон действует в редакции от 23 апреля 2019 г., вступившей в силу с 1 ноября 2019 г. [8].

Субъектами взыскания компенсации являются обладатели исключительного права на товарный знак, то есть предприниматели. При этом виды нарушений исключительного права, при которых применяется рассматриваемый способ защиты, 
в целом совпадают в российском (п. 3 ст. 1484 ГК РФ) и в китайском законодательстве. Так, согласно статье 57 Закона КНР «О товарных знаках» к нарушениям исключительного права на использование зарегистрированного товарного знака относятся, в частности, следующие действия: использование товарного знака, идентичного зарегистрированному товарному знаку, на однородных товарах, без должного разрешения правообладателя; использование на однородных товарах товарного знака, сходного с зарегистрированным, или использование обозначения, сходного с зарегистрированным товарным знаком, на схожих товарах, без должного разрешения правообладателя; реализация товаров, нарушающая исключительное право на использование зарегистрированного товарного знака; и др.

Способы определения размера компенсации регламентируются статьёй 63 Закона КНР «О товарных знаках», в соответствии с которой размер компенсации за нарушение исключительного права на товарный знак определяется исходя из фактических убытков, понесённых правообладателем в результате нарушения. Если фактические убытки определить сложно, допускается определение суммы компенсации по сумме дохода, полученного правонарушителем от противоправной деятельности. В случае же сложности определения суммы убытков правообладателя или дохода правонарушителя размер компенсации определяется с учётом кратной суммы лицензионных платежей за использование зарегистрированного товарного знака. При умышленном нарушении исключительного права на зарегистрированный товарный знак при наличии отягчающих обстоятельств допускается определение размера компенсации в сумме от однократной до пятикратной размеру сумм, определённых вышеназванными методами. Наконец, при невозможности определения суммы убытков правообладателя, дохода правообладателя или суммы лицензионных платежей за использование зарегистрированного товарного знака суд определяет сумму компенсации в зависимости от обстоятельств правонарушения в пределах 5 миллионов юаней.

Сравнительный анализ положений Закона КНР «О товарных знаках» и Гражданского кодекса РФ, регулирующих порядок взыскания компенсации, позволяет сделать следующие выводы.

Во-первых, в Китае применение судом установленных законом вариантов расчёта компенсации имеет определённую последовательность. В то же время согласно п. 4 ст. 1515 ГК РФ правообладатель вправе требовать по своему выбору от нарушителя возмещения убытков вместо выплаты компенсации: 1) в размере от десяти тысяч до пяти миллионов рублей, определяемом по усмотрению суда исходя из характера нарушения; 2) в двукратном размере стоимости товаров, на которых незаконно размещен товарный знак, или в двукратном размере стоимости права использования товарного знака, определяемой исходя из цены, которая при сравнимых обстоятельствах обычно взимается за правомерное использование 
товарного знака. Кроме того, до вынесения судом решения правообладатель может изменить выбранный им способ расчёта компенсации.

Во-вторых, выплата компенсации как мера ответственности за нарушение исключительного права на товарный знак по законодательству КНР подлежит применению при наличии вины нарушителя. Если лицо не знает о том, что проданный им товар нарушает исключительное право другой стороны на использование зарегистрированного товарного знака, и может доказать, что товары получены законными средствами, предоставив информацию о поставщиках товаров, оно не обязано выплачивать компенсацию (ст. 64 Закона КНР «О товарных знаках»). В свою очередь, в России положения законодательства о повышенной ответственности предпринимателей (п. 3 ст. 401 ГК РФ) распространены сейчас и на внедоговорные отношения. Выплата компенсации как мера ответственности за нарушение исключительного права на товарный знак, допущенное субъектом при осуществлении им предпринимательской деятельности, подлежит применению независимо от вины нарушителя, если такое лицо не докажет, что нарушение исключительного права произошло вследствие непреодолимой силы (абз. 3 п. 3 ст. 1250 ГК РФ). В иных случаях будет действовать общее правило о применении рассматриваемой санкции только к виновному субъекту.

В-третьих, в законодательстве КНР закреплён альтернативный порядок взыскания компенсации. Так, в случае спора по вопросу определения суммы компенсации за нарушение исключительного права на зарегистрированный товарный знак, если стороны не достигли компромисса путём переговоров, они вправе обратиться с заявлением о проведении медиации в Административный департамент промышленности и торговли или с иском в народный суд КНР. Кроме того, если стороны не достигли соглашения в результате медиации, правообладатель вправе также обратиться с иском в народный суд (статья 60 Закона КНР «О товарных знаках»). При этом только суд может принять решение о выплате компенсации в размере до 5 миллионов юаней при трудности определения фактических убытков.

В российском же законодательстве установлен исключительно судебный порядок взыскания компенсации (п. 1 ст. 1248 ГК РФ). В случае, если правообладатель и нарушитель исключительного права являются юридическими лицами и (или) индивидуальными предпринимателями, до предъявления иска о выплате компенсации обязательно предъявление правообладателем претензии (п. 5.1 ст. 1252 ГК РФ).

В-четвёртых, компенсация по китайскому законодательству рассматривается скорее не как особая мера гражданско-правовой ответственности, а как способ возмещения убытков, при котором правообладатель обязан доказывать их размер. Более того, если правообладатель не смог подтвердить причинение ему убытков в результате правонарушения, то лицо, обвиняемое в нарушении исключительного 
права на товарный знак, освобождается от ответственности (ст. 64 Закона КНР «О товарных знаках»).

Сложность доказывания заключается в том, что бухгалтерские документы и другие материалы, связанные с расчётом суммы убытков, находятся под контролем предполагаемого нарушителя, вследствие чего истец не может предоставить достаточные доказательства в обоснование своего иска. По указанной причине в законе было закреплено специальное правило, применяемое при «воспрепятствовании доказательствам». Согласно ст. 63 Закона КНР «О товарных знаках» народный суд с целью определения суммы ущерба может потребовать от нарушителя предоставить бухгалтерские книги и материалы, связанные с нарушениями. Если же нарушитель не предоставляет указанные документы либо предоставляет фальшивые материалы, народный суд может вынести решение о размере убытков со ссылкой на требования правообладателя и представленные им доказательства. Указанное правило действует при условии, что правообладатель приложил все усилия для сбора доказательств и при этом не нарушил требования об охране информации, связанной с коммерческой тайной [9, с. 130].

В свою очередь, согласно абз. 1 п. 2 ст. 1252 ГК РФ правообладатель, обратившийся с требованием о выплате компенсации, освобождается от доказывания размера причинённых ему убытков. Таким образом, в предмет доказывания по требованиям о выплате компенсации за нарушение исключительного права на товарный знак входят следующие обстоятельства: факт принадлежности истцу указанного права и факт его нарушения ответчиком путём индивидуализации товаров, работ или услуг, в отношении которых товарный знак зарегистрирован, или однородных им, если в результате такого использования возникает вероятность смешения. Следовательно, правообладатель, обратившийся за защитой права на товарный знак, освобождается от доказывания причинённых ему убытков и их размера. Вместе с тем, вероятные имущественные потери правообладателя могут иметь значение в качестве подлежащего учёту обстоятельства дела при определении судом размера компенсации. Поэтому, заявляя требование о взыскании компенсации в размере от десяти тысяч до пяти миллионов рублей, истец должен предоставить обоснование размера взыскиваемой суммы [10, п. 61].

В-пятых, в китайской доктрине и судебной практике превалирует «штрафной» (карательный) подход к правовой природе компенсации за нарушение исключительного права на товарный знак. Исследуемую категорию в научных работах и судебных решениях обозначают «штрафной компенсацией», «карательной компенсацией», «штрафными убытками», «экономическими убытками» [11, с. 148].

К примеру, учёный Чжан Хун, обосновывая штрафную природу компенсации, высказал мнение, что карательная компенсация в области интеллектуальной собственности применяется ввиду особого характера интеллектуальных прав. Автор от- 
метил, что сложность и неопределённость рынка создаёт естественные препятствия для оценки стоимости интеллектуальных прав и затрудняет определение ущерба владельцу товарного знака. Поэтому для нематериальных активов, таких как товарные знаки, применение карательной системы является обоснованным [12, с. 164].

Заметим, что законодательное регулирование в сфере взыскания компенсации в Китае менялось в сторону определённого ужесточения на фоне изменения внутренней политики КНР, связанной, в том числе, с продвижением инноваций и усилением охраны интеллектуальных прав. Так, сумма компенсации в случаях, если доходы нарушителя или убытки правообладателя от нарушения установить затруднительно, за последние годы выросла с трёх до пяти миллионов юаней.

Вместе с тем, восстановительный характер компенсации также принимается во внимание судами КНР при рассмотрении соответствующих споров. К примеру, отменяя решение суда первой инстанции и вынося решение о более высоком размере компенсации за нарушение исключительного права на товарный знак компании Budweiser (China) Sales Co., Ltd. (180 тысяч юаней, включая разумные расходы правообладателя, уплаченные для прекращения нарушения), суд второй инстанции отметил, что факты, установленные в первоначальном решении, были очевидны, но размер компенсации не смог компенсировать убытки правообладателя и наказать за нарушение [13]. Более того, как отмечалось, изначально размер компенсации за нарушение исключительного права на товарный знак определяется исходя из фактических убытков, понесённых правообладателем в результате нарушения.

В то же время в российской судебной практике наметилась устойчивая тенденция к снижению размера компенсации. Такая возможность установлена в абз. 3 п. 3 ст. 1252 ГК РФ, в частности, для случаев нарушения прав на несколько товарных знаков одного правообладателя, неправомерно размещённых на товаре. В подобных ситуациях общий размер компенсации может быть снижен судом ниже пределов, установленных ГК РФ, но не может составлять менее 50 \% суммы минимальных размеров всех компенсаций за допущенные нарушения. При этом в абз. 3 п. 65 Постановления Пленума Верховного суда РФ от 23 апреля 2019 г. № 10 «О применении части четвёртой Гражданского кодекса Российской Федерации» разъясняется, что распространение нескольких материальных носителей при неправомерном использовании одного результата интеллектуальной деятельности или средства индивидуализации составляет одно правонарушение, если такое нарушение охватывается единством намерений нарушителя [10, п. 65].

В свою очередь, Конституционный Суд РФ, рассматривая вопрос о снижении размера компенсации, пришёл к выводу о том, что, будучи штрафной санкцией, взыскание компенсации «является частноправовым институтом, который основывается на признании равенства участников регулируемых им отношений...» (п. 4.2 Постановления Конституционного Суда РФ от 13 декабря 2016 г. № 28-П). В этой связи 
Конституционный Суд РФ указал на возможность снижения компенсации, начисленной за нарушение одним действием прав на несколько объектов, ниже установленного законом предельного размера, если размер подлежащей взысканию компенсации многократно превышает размер причинённых правообладателю убытков и если при этом обстоятельства конкретного дела свидетельствуют, в частности, о том, что правонарушение совершено индивидуальным предпринимателем впервые и что использование объектов интеллектуальной собственности, права на которые принадлежат другим лицам, с нарушением этих прав не являлось существенной частью его предпринимательской деятельности и не носило грубый характер [2] .

Приведённые правовые позиции по вопросу снижения размера компенсации нашли отражение в судебной практике [14; 15]. Так, при рассмотрении исковых требований $\mathrm{AO}$ «Сеть телевизионных станций» к индивидуальному предпринимателю о взыскании компенсации в размере 80 тысяч рублей за нарушение исключительных прав на три товарных знака и произведение изобразительного искусства, принадлежащие истцу, суд первой инстанции пришёл к выводу о том, что нарушение ответчиком исключительных прав истца путём реализации двух товаров, приобретённых в двух разных торговых точках в течение короткого промежутка времени, охватывалось единством его намерений и с учётом правовой позиции, приведённой в п. 65 Постановления Пленума Верховного суда РФ от 23 апреля 2019 № 10, может быть рассмотрено как один случай незаконного использования исключительных прав. Применив положения абз. 3 п. 3 ст. 1252 ГК РФ, суд снизил размер компенсации за каждое нарушение до 5 тысяч рублей, взыскав 20 тысяч рублей компенсации. Указанное решение было поддержано 14 Арбитражным апелляционным судом и оставлено без изменений Судом по интеллектуальным правам [16].

В-шестых, критерии определения размера компенсации можно вывести из положений ст. 63 Закона КНР «О товарных знаках». В первую очередь, суды ориентируются на размер фактических убытков правообладателя в результате нарушения права на товарный знак либо на прибыль, полученную ответчиком в результате правонарушения. Так, основываясь на доказательствах, представленных сторонами в деле о взыскании компенсации за нарушение прав на товарный знак «CHANEL» по иску компании Chanel Co., Ltd. к пяти соответчикам, суд снизил размер компенсации (экономических убытков) с 60 тысяч юаней до 30 тысяч юаней [17].

Кроме того, при определении размера компенсации учитывается степень вины нарушителя, а также неоднократность нарушения, срок незаконного использования товарного знака и другие отягчающие обстоятельства. При умышленном нарушении исключительного права на товарный знак с учётом указанных обстоятельств возможно кратное увеличение размера компенсации. Например, суд поддержал исковые требования компании Balanced Body Inc. в споре о нарушении прав на товарный знак «MOTR» и взыскал с ответчика 3 миллиона юаней экономических убытков, представ- 
ляющих собой штрафную компенсацию, рассчитанную исходя из доходов ответчика от правонарушения. При определении суммы компенсации суд учёл умысел ответчика и неоднократность нарушения исключительного права на товарный знак [18].

Наконец, при невозможности расчёта суммы убытков суд определяет размер компенсации в зависимости от характера допущенного правонарушения. Анализ судебной практики КНР в указанной области показывает, что нарушение исключительного права характеризуют такие обстоятельства, как масштаб противоправного действия (объём выпуска контрафактных товаров с использованием товарного знака; нарушение деловой репутации правообладателя и т. д.). Данный критерий может определяться и спецификой объекта интеллектуальной собственности, право на который было нарушено. Так, суд взыскал по иску компании Commercial Press Co., Ltd. с ответчика значительную компенсацию в размере 3 миллиона юаней, в частности, с учётом того обстоятельства, что товарный знак «Словарь Синьхуа», права на который были нарушены, имел режим общеизвестного товарного знака [19].

При определении размера компенсации суды принимают во внимание и другие обстоятельства, например, недобросовестное поведение ответчика, представляющее собой акт недобросовестной конкуренции. Отметим, что в споре о нарушении прав на товарный знак и недобросовестной конкуренции между компаниями China Neighbor International Cultural Exchange Co., Ltd. и Ai Shang TV Media Co., Ltd. действия ответчика признаны судом добросовестными и требование истца о компенсации в размере 500 тысяч юаней было отклонено [20].

В России, как и в КНР, размер подлежащей взысканию компенсации должен быть судом обоснован. Критерии и обстоятельства, учитываемые при определении размера компенсации за нарушение исключительного права, были обобщены в Постановлении Пленума Верховного Суда РФ от 23.04. 2019 № 10 «О применении части четвёртой Гражданского кодекса Российской Федерации». Согласно п. 62 указанного документа по требованиям о взыскании компенсации в размере от десяти тысяч до пяти миллионов рублей суд определяет сумму компенсации исходя из представленных сторонами доказательств не выше заявленного истцом требования. При этом при определении размера компенсации суд учитывает, в частности, обстоятельства, связанные с объектом нарушенных прав (например, его известность публике), характер допущенного нарушения (например, размещён ли товарный знак на товаре самим правообладателем или третьими лицами без его согласия, осуществлено ли воспроизведение экземпляра самим правообладателем или третьими лицами и т. п.), срок незаконного использования результата интеллектуальной деятельности или средства индивидуализации, наличие и степень вины нарушителя (в том числе носило ли нарушение грубый характер, допускалось ли оно неоднократно), вероятные имущественные потери правообладателя и некоторые другие факторы [10, п. 62]. 
Анализ российской судебной практики последних лет показывает, что при определении размера компенсации за нарушение исключительного права на товарный знак суды чаще всего ссылаются на характер правонарушения; соразмерность последствиям допущенного ответчиком нарушения; соответствие размера компенсации принципам разумности и справедливости [21]; вероятные убытки правообладателя; отсутствие ранее совершённых ответчиком нарушений исключительного права [22]; неоднократность нарушения исключительного права на товарный знак [23].

Резюмируя вышеизложенное, следует подчеркнуть, что взыскание компенсации за нарушение исключительного права на товарный знак закреплено как в законодательстве России, так и в законодательстве КНР в качестве меры гражданско-правовой ответственности, обладающей рядом схожих характеристик. Так, выплата компенсации по законодательству обеих стран является способом защиты только исключительного права, а не иных интеллектуальных прав. В целом совпадают критерии определения размера компенсации, а также некоторые варианты её расчёта (определение размера компенсации с учётом кратной суммы лицензионных платежей за использование зарегистрированного товарного знака).

В то же время, имеются и определённые различия в правовом регулировании порядка выплаты компенсации, а также в особенностях применения данного способа защиты гражданских прав в судебной практике. К примеру, в российской правоприменительной практике существует определённый баланс между восстановительной и штрафной функцией рассматриваемой санкции, тогда как в КНР штрафная природа компенсации в определённых случаях выходит на первый план. Далее, в отличие от Закона КНР «О товарных знаках», в ГК РФ закреплено освобождение правообладателя от доказывания размера причинённых ему убытков (п. 3 ст. 1252 ГК РФ), что, безусловно, облегчает применение данного способа защиты. Положительным нововведением можно считать применение выплаты компенсации за нарушение исключительного права на товарный знак независимо от вины нарушителя при осуществлении им предпринимательской деятельности (п. 3 ст. 1250 ГК РФ), тогда как в Китае невиновность нарушителя исключительного права освобождает его от ответственности (ст. 64 Закона КНР «О товарных знаках»).

Вместе с тем, в законодательстве КНР закреплены положения, представляющие, на наш взгляд, интерес для российских правоприменителей. Так, согласно ст. 63 Закона КНР «О товарных знаках» сумма компенсации должна включать обоснованные расходы, понесённые правообладателем для пресечения правонарушения. В свою очередь, в ст. 64 указанного закона достаточно чётко определены обстоятельства, которые могут и освободить нарушителя от ответственности, и повлиять на определение размера компенсации. В частности, если правообладатель не может предоставить доказательства использования товарного знака, то лицо, обвиняемое в нарушении исключительного права на товарный знак, осво- 
бождается от ответственности. В то же время, в ГК РФ (ст. 1486) неиспользование товарного знака может привести к досрочному прекращению его правовой охраны, но как основание освобождения нарушителя от ответственности, в том числе при взыскании компенсации, в законе не закреплено.

Таким образом, полагаем, что и законодательство России, и законодательство Китая в области правового регулирования выплаты компенсации за нарушение исключительного права на товарный знак должно совершенствоваться с учётом положительного опыта обеих стран.

\section{Список литературы}

1. Новосёлова, Л. А. Принцип справедливости и механизм компенсации как средство защиты исключительных прав // Вестник гражданского права. - 2017. № 2. - C. $48-55$.

2. По делу о проверке конституционности подпункта 1 статьи 1301, подпункта 1 статьи 1311 и подпункта 1 пункта 4 статьи 1515 Гражданского кодекса Российской Федерации в связи с запросами Арбитражного суда Алтайского края : постановление Конституционного Суда РФ от 13 декабря 2016 г. № 28-П // Собрание законодательства Российской Федерации. - 2016. - № 52 (ч. 5). - Ст. 7729.

3. По делу о проверке конституционности подпункта 2 пункта 4 статьи 1515 Гражданского кодекса Российской Федерации в связи с запросом Пятнадцатого Арбитражного Апелляционного суда : постановление Конституционного Суда РФ от 24 июля 2020 г. № 40-П // Собрание законодательства Российской Федерации. 2020. - № 32. - Ст. 5362.

4. Хохлов, В. А. Авторское право: законодательство, теория, практика / В. А. Хохлов. - Москва : Городец, 2008. -286 с.

5. Сергеев, А. П. Правовая природа компенсации за нарушение исключительного авторского права // Гражданское законодательство : Статьи. Комментарии. Практика. Вып. 50 / под ред. А. Г. Диденко. - Алматы, 2017. - С. 68-79.

6. Компенсация за нарушение исключительных прав: вопросы квалификации // Закон. - 2016. - № 12. - С. 18-28.

7. Право интеллектуальной собственности. Т. 3 : Средства индивидуализации : учебник / под общ. ред. Л. А. Новосёловой. - Москва : Статут, 2018. - 432 с.

8. Закон о товарных знаках Китайской Народной Республики от 23 августа 1982 г., с поправками от 22 февраля 1993 г., 27 октября 2001 г., 30 августа 2013 г., 23 апреля 2019 г. - URL: https://wipolex.wipo.int/ru/text/579989 (дата обращения: 21.05.2021).

9. У Ханьдун. Презумпция ответственности за вину и определение размера компенсации в судебном разбирательстве о нарушении прав интеллектуальной собственности: с точки зрения верховенства бремени доказывания // Обзор законодательства. - 2014. - Вып. 5. - С. 130. - Кит. 
10. О применении части четвёртой Гражданского кодекса Российской Федерации : постановление Пленума Верховного суда РФ от 23 апреля 2019 г. № 10. - URL: http://www.consultant.ru/document/cons_doc_LAW_323470/(дата обращения: 21.05.2021).

11. Ян Цзяньлунь. Судебное применение возмещения убытков по делам о нарушении прав на товарные знаки на фоне нового Закона «О товарных знаках Китая» // Legal System Expo. - 2020. - Январь, ч. 2. - С. 148. - Кит.

12. Чжан Хун. Карательная компенсация за злонамеренное нарушение прав на товарный знак // Юридические и коммерческие исследования. - 2019. - Вып. 4. С. 164. - Кит.

13. China Judgments Online. - URL: https://wenshu.court.gov.cn/website/wens hu/181010CARHS5BS3C/index.html? (дата обращения: 21.05.2021).

14. Постановление Суда по интеллектуальным правам от 10 февраля 2021 г. N C0151/2021 по делу № A05-6394/2020. - URL: http://www.consultant.ru/cons/cgi/online.cgi? req=doc;base=SIP; $n=73109 \# 09010569712438272$ (дата обращения: 21.05.2021).

15. Постановление Суда по интеллектуальным правам от 29 января 2021 г. по делу № A71-17369/2019. - URL: http://www.consultant.ru (дата обращения: 21.05.2021).

16. Постановление Суда по интеллектуальным правам от 11 февраля 2021 г. по делу № A05-6698/2020. - URL: http://www.consultant.ru (дата обращения: 21.05.2021).

17. China Judgments Online. - URL: https://wenshu.court.gov.cn/website/ wenshu/181107ANFZ0BXSK4/index.html?docId=70cdf2c8254e4d469304ab8e00c2fle7 (дата обращения: 21.05.2021).

18. China Judgments Online. - URL: https://wenshu.court.gov.cn/website/wenshu/ 181107ANFZ0BXSK4/index.html?docId=15cc07a476ac4b47a5ffab0200c28c6c (дата обращения: 21.05.2021).

19. China Judgments Online. - URL: https://wenshu.court.gov.cn/website/we nshu/181107ANFZ0BXSK4/index.html?docId=de9a1db504a34321a3a2a9bb0011552a (дата обращения: 21.05.2021).

20. China Judgments Online. - URL: https://wenshu.court.gov.cn/website/wen shu/181 107ANFZ0BXSK4/index.html?docId=0fd7ad3ce45a4628aabca857012742b5 (дата обращения: 21.05.2021).

21. Постановление Тринадцатого арбитражного апелляционного суда от 27 октября 2020 г. № 13 АП-25959/2020 по делу A56-136561/2019. - URL: http://www.con sultant.ru (дата обращения: 21.05.2021).

22. Постановление Первого арбитражного апелляционного суда от 15 сентября 2020 г. по делу № A11-12111/2019. - URL: http://www.consultant.ru (дата обращения: 21.05.2021).

23. Постановление Четырнадцатого арбитражного апелляционного суда от 20 октября 2020 г. по делу № A05-6411/2020. - URL: http://www.consultant.ru (дата обращения: 21.05.2021). 


\section{References}

1. Novoselova L.A. Printsip spravedlivosti i mekhanizm kompensatsii kak sredstvo zashchity isklyuchitel'nykh prav [The principle of justice and the mechanism of compensation as a means of protecting exclusive rights]. Vestnik grazhdanskogo prava, 2017, no. 2 , pp. $48-55$.

2. In the case of checking the constitutionality of subparagraph 1 of Article 1301, subparagraph 1 of Article 1311 and subparagraph 1 of paragraph 4 of Article 1515 of the Civil Code of the Russian Federation in connection with the requests of the Arbitration Court of the Altai Territory: Resolution of the Constitutional Court of the Russian Federation of December 13, 2016 No. 28-P. Collected Legislation of the Russian Federation, 2016, no. 52 (part 5), art. 7729. (In Russian).

3. In the case of checking the constitutionality of subparagraph 2 of paragraph 4 of Article 1515 of the Civil Code of the Russian Federation in connection with the request of the Fifteenth Arbitration Court of Appeal: Resolution of the Constitutional Court of the Russian Federation of July 24, 2020 No. 40-P. Collected Legislation of the Russian Federation, 2020, no. 32, art. 5362. (In Russian).

4. Khokhlov V. A. Avtorskoe pravo: zakonodatel'stvo, teoriya, praktika [Copyright: legislation, theory, practice]. Moscow: Gorodets Publ., 2008. 286 p.

5. Sergeev A. P. Pravovaya priroda kompensatsii za narushenie isklyuchitel'nogo avtorskogo prava [Legal nature of compensation for violation of exclusive copyright]. In: Grazhdanskoe zakonodatel'stvo: Stat'i. Kommentarii. Praktika. [Didenko A.G., ed. Civil legislation: Articles. Comments. Practice]. Iss. 50. Almaty, 2017, pp. 68-79.

6. Compensation for violation of exclusive rights: qualification issues. Zakon, 2016, no. 12, pp. 18-28. (In Russian).

7. Novoselova L. A., ed. Pravo intellektual'noi sobstvennosti. T. 3 : Sredstva individualizatsii [Intellectual property rights. Vol. 3: Means of individualization: textbook ]. Moscow: Statute Publ., 2018. 432 p.

8. Law on Trademarks of the People's Republic of China of August 23, 1982, as amended on February 22, 1993, October 27, 2001, August 30, 2013, April 23, 2019 Available at: https://wipolex.wipo.int/ ru/ text/579989 (accessed 21 May 2021). (In Russian).

9. Wu Handong. Presumption of responsibility for guilt and determination of the amount of compensation in litigation on infringement of intellectual property rights: from the point of view of the supremacy of the burden of proof. Review of legislation, 2014, iss. 5, pp. 130. (In Chinese).

10. On the application of part four of the Civil Code of the Russian Federation: Resolution of the Plenum of the Supreme Court of the Russian Federation of April 23, 2019 No. 10. Available at: http://www.consultant.ru/document/cons_doc_LAW_323470/ (accessed 21 May 2021). (In Russian). 
11. Yang Jianlun. Judicial application of damages in cases of violation of rights to trademarks against the background of the new Law "On China Trademarks". Legal System Expo, 2020, January, part 2, pp. 148. (In Chinese).

12. Zhang Hong. Punitive compensation for malicious violation of trademark rights. Legal and Commercial Research, 2019, iss. 4, pp. 164. (In Chinese).

13. China Judgments Online. Available at: https://wenshu.court.gov.cn/website/we shu/181010CARHS5BS3C/index.html? (accessed 21 May 2021).

14. Ruling of the Intellectual Property Rights Court dated February 10, $2021 \mathrm{~N} \mathrm{C01-}$ 51/2021 in case No. A05-6394/2020. Available at: http://www.consultant.ru/cons/cgi/onl ine.cgi?req $=$ doc;base $=$ SIP; $=73109 \# 09010569712438272$ (accessed 21 May 2021). (In Russian).

15. Ruling of the Intellectual Property Court dated January 29, 2021 in case No. A7117369/2019. Available at: http://www.consultant.ru (accessed 21 May 2021). (In Russian).

16. Judgment of the Intellectual Property Court dated February 11, 2021 in case No. A05-6698/2020. Available at: http://www.consultant.ru (accessed 21 May 2021).

17. China Judgments Online. Available at: https://wenshu.court.gov.cn/website/w enshu/181107ANFZ0BXSK4/index.html?docId=70cdf2c8254e4d469304ab8e00c2f1e7 (accessed 21 May 2021).

18. China Judgments Online. Available at: https://wenshu.court.gov.cn/website/wen shu/181107ANFZ0BXSK4/index.html?docId=15cc07a476ac4b47a5ffab0200c28c6c (accessed 21 May 2021).

19. China Judgments Online. Available at: https://wenshu.court.gov.cn/website/wen shu/181107ANFZ0BXSK4/index.html?docId=de9a1db504a34321a3a2a9bb0011552a (accessed 21 May 2021).

20. China Judgments Online. Available at: https://wenshu.court.gov.cn/websi te/wenshu/181107ANFZ0BXSK4/index.html?docId=0fd7ad3ce45a4628aabca857012742 b5 (accessed 21 May 2021).

21. Resolution of the Thirteenth Arbitration Court of Appeal dated October 27, 2020 No. 13 AP-25959/2020 in case A56-136561/2019. Available at: http://www.consultant.ru (accessed 21 May 2021). (In Rissian).

22. Resolution of the First Arbitration Court of Appeal dated September 15, 2020 in case No. A11-12111/2019. Available at: http://www.consultant.ru (accessed 21 May 2021).

23. Resolution of the Fourteenth Arbitration Court of Appeal dated October 20, 2020 in case No. A05-6411/2020. Available at: http://www.consultant.ru (accessed 21 May 2021). 